\title{
A More Relevant Dissolution Method for Evaluation of Floating Drug Delivery System
}

\author{
Mukesh C. Gohel ${ }^{1,2}$, Pavak R. Mehta ${ }^{2}$, Rikita K. Dave² and Nehal H. Bariya²
}

\begin{abstract}
The study objective was to develop a more relevant in vitro dissolution method to evaluate a carbamazepine floating drug delivery system. A 100-mL glass beaker was modified by adding a side arm at the bottom of the beaker so that the beaker can hold $70 \mathrm{ml}$ of $0.1 \mathrm{~N} \mathrm{HCl}$ dissolution medium and allow collection of samples. A burette was mounted above the beaker to deliver the dissolution medium at a flow rate of $2 \mathrm{~mL} / \mathrm{min}$ to mimic gastric acid secretion rate. Carbamazepine floating tablets were prepared by wet granulation technique. The performance of the modified dissolution apparatus was compared with USP dissolution Apparatus 2 (Paddle). The problem of adherence of the tablet to the shaft of the paddle was observed with the USP dissolution apparatus. The tablet did not stick to the agitating device in the proposed dissolution method. The drug release followed zero-order kinetics in the proposed method. Similarity of dissolution curves was observed between the USP method and the proposed method at $10 \%$ difference level $\left(f_{2}=57\right)$. However, the dissolution profiles were found to be dissimilar at $5 \%$ level. The proposed test may show good in vitro-in vivo correlation since an attempt is made to mimic the in vivo conditions such as gastric volume, gastric emptying, and gastric acid secretion rate.
\end{abstract}

\section{Introduction}

A modified release drug delivery system with prolonged residence time in the stomach is of particular interest for drugs: (a) that are locally acting in the stomach, (b) that have an absorption window in the stomach or in the upper part of small intestine, (c) that are unstable in the intestinal or colonic environments, or (d) have low solubility at high $\mathrm{pH}$ values. Systems that prolong the gastric residence time can also be used as sustained release devices with a reduced frequency of administration and therefore, can improve patient compliance (1). Approaches to increase gastric residence time include: (a) bioadhesive delivery systems that adhere to mucosal surfaces, (b) delivery systems that increase in size to retard passage through the pylorus, and (c) density-controlled delivery systems, that either float or sink in gastric fluids (2-6).

In vitro dissolution testing is generally carried out for quality control purposes and to establish an in vivo in vitro correlation. Traditional in vitro dissolution methods have been shown to be poor predictors of in vivo performance for floating dosage forms (7).The currently used in vitro dissolution methods do not mimic the conditions present in the stomach. Researchers around the world have tried different methods for studying in vitro dissolution for floating drug delivery systems $(8,9)$. However, each of the methods has some limitations. Hence, a modified in-vitro dissolution method was evaluated.

\section{Materials and Methods \\ Materials}

Carbamazepine (Intas Pharmaceutical Ltd., Ahmedabad), hydroxypropyl methylcellulose K4M (Torrent Phar-

\footnotetext{
${ }^{1}$ Corresponding author, email: mukeshgohel@hotmail.com

2 Department of Pharmaceutics and Pharmaceutical Technology, L. M.

College of Pharmacy, Ahmedabad 380 009, India
}

maceuticals Ltd., Ahmedabad), sodium bicarbonate (Samir Tech. Chem. Pvt. Ltd., Ahmedabad), citric acid (S. D. Fine Chem. Ltd., Boisar), magnesium stearate (Apex Chemicals, Ahmedabad) and alcohol (Baroda Chemical Industries Ltd., Dabhoi) were used as received.

\section{Preparation of floating tablets}

Carbamazepine (100 mg), hydroxypropyl methylcellulose (HPMC, $81.25 \mathrm{mg}$ ), sodium bicarbonate $(20.83 \mathrm{mg}$ ) and citric acid (10.42 mg) were mixed thoroughly. Alcoholic solution of HPMC ( $1 \% \mathrm{w} / \mathrm{v})$ was used as a granulating agent. The granules ( 40 mesh) were dried in a conventional hot air oven (CINTEX, Ahmedabad) at $45^{\circ} \mathrm{C}$. The dried granules were sieved through 40/60 mesh. Magnesium stearate $(0.6 \%)$ was added as a lubricant and the granules were compressed into tablets using a single stroke tablet machine (Cadmach Machinery Ltd., Ahmedabad).

\section{Modified dissolution method}

A glass beaker (100-ml capacity) was modified at the base by adding an $\mathrm{S}$-shaped glass tube so that the glass beaker can hold $70 \mathrm{ml}$ of dissolution medium. The medium was stirred on a magnetic stirrer. A burette was mounted above the beaker to deliver the dissolution medium at a flow rate of $2 \mathrm{ml} / \mathrm{min}$.

\section{Dissolution study of carbamazepine tablets}

The carbamazepine tablet was put in the modified beaker containing $70 \mathrm{ml}$ of $0.1 \mathrm{~N} \mathrm{HCl}$. After about $2 \mathrm{~min}$, the time required for floating of the tablet, the contents were stirred at a speed of $75 \mathrm{rpm}$. The temperature of the dissolution medium was maintained at $37 \pm 0.5^{\circ} \mathrm{C}$. From a burette, $0.1 \mathrm{~N} \mathrm{HCl}$ was added at the rate of $2 \mathrm{ml} / \mathrm{min}$. The dissolution medium along with the dissolved drug came out of the side arm provided at the base of the beaker at the rate of $2 \mathrm{ml} / \mathrm{min}$. Samples of $5 \mathrm{ml}$ were collected at a 


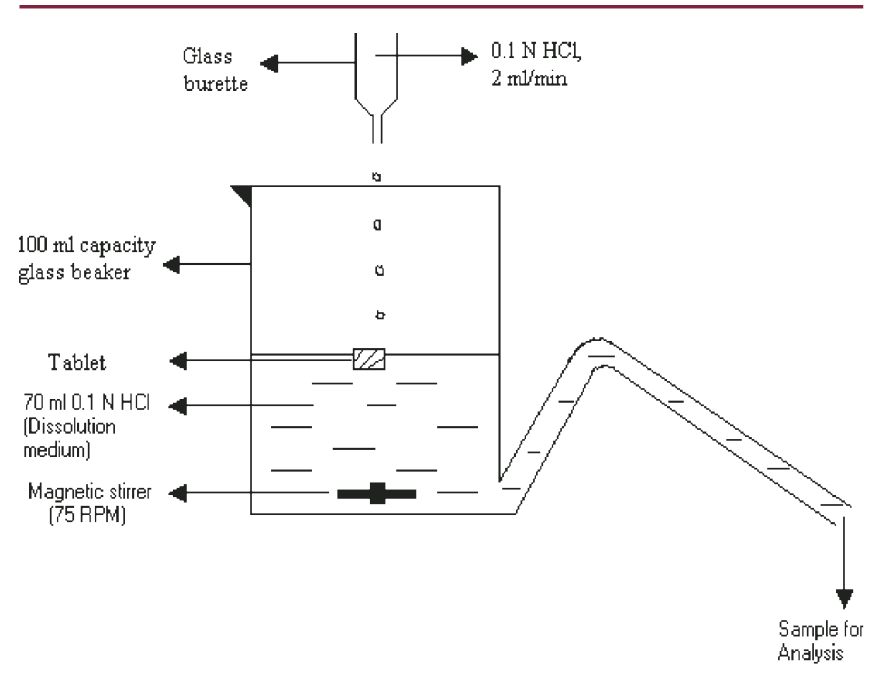

Figure I. Schematic presentation of the proposed method.

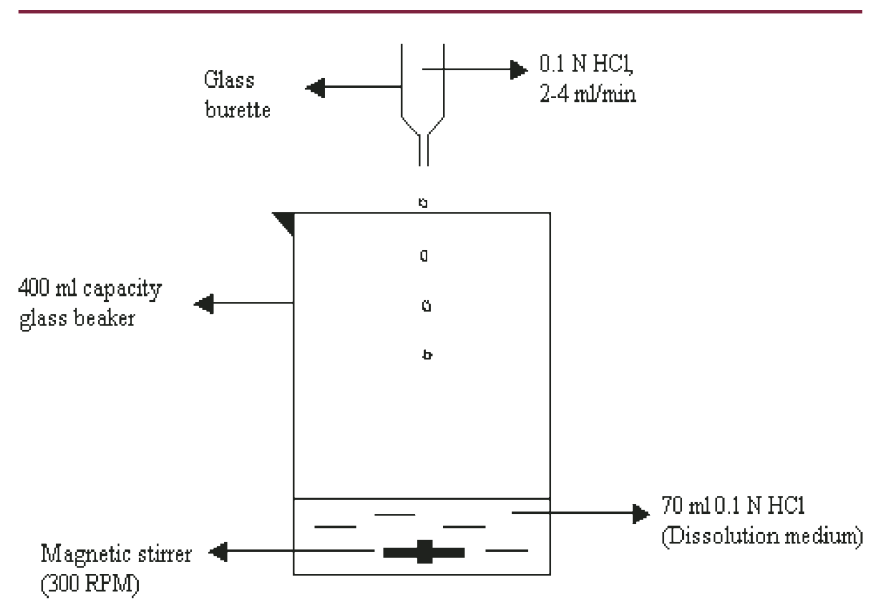

Figure II. Schematic presentation of Rossett-Rice test.

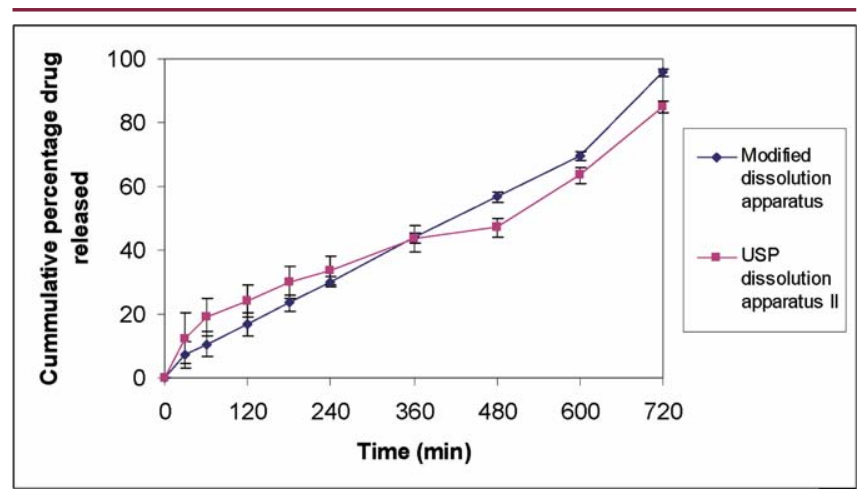

Figure III. Comparative drug release profile.

specific time interval (e.g. 30,60, 120, 180, 240, 360, 480, 600 and $720 \mathrm{~min}$ ) to analyze the drug content in the dissolution medium. All the samples were passed through a 0.5 $\mu \mathrm{m}$ filter paper and then analyzed using UV/Vis spec-

\section{Table l: Comparative drug release profile of} carbamazepine floating tablet.

\begin{tabular}{|ccc|}
\hline \multirow{2}{*}{$\begin{array}{l}\text { Time } \\
(\min )\end{array}$} & \multicolumn{2}{c|}{ Cumulative percentage drug release } \\
\cline { 2 - 3 } & Modified apparatus & USP apparatus 2 \\
\hline 30 & 0 & 0 \\
\hline 60 & 7.11 & 12.49 \\
\hline 120 & 10.59 & 19.12 \\
\hline 180 & 16.75 & 24.12 \\
\hline 240 & 23.43 & 29.96 \\
\hline 360 & 30.06 & 33.67 \\
\hline 480 & 43.98 & 43.63 \\
\hline 600 & 56.6 & 47.05 \\
\hline 720 & 69.51 & 63.52 \\
\hline Similarity factor $\left(\mathrm{f}_{2}\right)$ & 957 & 85.01 \\
\hline
\end{tabular}

trophotometer (Hitachi U2000, Japan) at $285 \mathrm{~nm}$. The dissolution study was also carried out using USP dissolution Apparatus 2 (Paddle, $900 \mathrm{~mL} 0.1 \mathrm{~N} \mathrm{HCl}, 37 \pm 0.5^{\circ} \mathrm{C}, 75$ rpm).

\section{Results and discussion \\ Carbamazepine floating tablets}

Carbon dioxide is formed within the tablet containing effervescent agent when the carbamazepine tablet is brought in contact with the acidic dissolution medium. The low density of hydroxypropyl methylcellulose assists in floating the carbamazepine tablet. . Moreover, the gelling capacity of HPMC also helps float the tablet by entrapping carbon dioxide gas in the gel network of HPMC. The gelling capacity of HPMC prevents disintegration of the tablet during the dissolution study and thus sustained drug release occurs. The formulation shown in the experimental section is an optimum formulation selected from a simplex lattice design. The tablets showed a lag time, the time required for flotation of the tablet was 2 minutes.

\section{Modified dissolution apparatus}

The proposed method is essentially a modification of the Rossett-Rice test (10), which is a popular in vitro test for evaluating the acid neutralization efficiency of antacids. Antacids are short acting compounds and therefore the Rossett-Rice test is carried out in a conventional beaker for a period of about 30-60 minutes, while the floating drug delivery systems are generally meant for obtaining sustained effect and therefore modification is necessary at the bottom of the beaker. In the proposed method, a gastric emptying phenomenon is mimicked by providing a 
Table II: Comparison between different dissolution methods.

\begin{tabular}{|c|c|c|}
\hline Sr. No. & Method & Comment \\
\hline 1. & USP (Apparatus 2) & $\begin{array}{l}\text { 1. Volume of dissolution medium }(900 \mathrm{~mL}) \text { is very high as compared to stomach content. } \\
\text { 2. Adherence of dosage form on the shaft. } \\
\text { 3. Problem in sample collection (overdriven arrangement). } \\
\text { 4. The test does not mimic the release of acid from stomach lining and gastric emptying } \\
\text { through pylorus opening. }\end{array}$ \\
\hline 2. & USP (Apparatus 4) $(11,12)$ & $\begin{array}{l}\text { 1. The dosage form remains stationary during the test in the cell and hence floating ability } \\
\text { cannot be examined effectively. } \\
\text { 2. Generally, a high flow rate }(50 \mathrm{~mL} / \mathrm{min}) \text { is used. }\end{array}$ \\
\hline 3. & Burns (8) & $\begin{array}{l}\text { 1. Adherence of dosage form to the stainless steel mesh. } \\
\text { 2. Volume of dissolution medium }(900 \mathrm{~mL}) \text { is very high as compared to stomach content. }\end{array}$ \\
\hline 4. & Durig and Fassihi (9) & 1. The tablet may adhere to double mesh wire device. \\
\hline 5. & Proposed method & $\begin{array}{l}\text { 1. The test tries to mimic the gastric juice release rate }(2-4 \mathrm{~mL} / \mathrm{min} \text { ) and gastric emptying } \\
\text { though pylorus opening (since constant level device was used). } \\
\text { 2. The problem of sticking of dosage form on the agitating device is avoided (under-driven } \\
\text { arrangement). } \\
\text { 3. The sample collection is easy. } \\
\text { 4. Volume is } 70 \mathrm{~mL} \text { (comparable to in vivo gastric volume). }\end{array}$ \\
\hline
\end{tabular}

Table III: Comparison between different dissolution methods.

\begin{tabular}{|lll|}
\hline Criteria & Rossett-Rice test & Proposed method \\
\hline Rate of agitation & High $(300-400 \mathrm{rpm})$ & Low $(70-75 \mathrm{rpm})$ \\
\hline Duration of testing & $30-60 \mathrm{~min}$ & $10-12 \mathrm{hr}$ \\
\hline Closeness to in vivo conditions & No & Yes \\
\hline Size of vessel & Large $(400 \mathrm{~mL}$ capacity) & Small (100 mL capacity) \\
\hline Closeness to flow through cell & No & Yes \\
\hline Application & Antacids and anti reflux formulations & Floating drug delivery system \\
\hline
\end{tabular}

side arm at the bottom of the beaker. The test also tries to simulate the conditions of a flow-through cell with respect to availability of fresh dissolution medium around the dosage form. High stirring rate $(300 \mathrm{rpm})$ is used in the Rossett-Rice test as compared to the current practice of low speed stirring (50-100 rpm) in the USP paddle apparatus. In short, the modified test tries to mimic the gastric volume $(70 \mathrm{ml})$, gastric acid secretion rate $(2 \mathrm{ml} / \mathrm{min})$ and emptying of liquid through pylorus opening. Figures I and Il depict the schematic representation of the modified dissolution vessel and Rossett-Rice method respectively.

\section{Dissolution testing}

Figure III and Table I show that the drug was released at a slightly slower rate in the proposed method as compared to USP dissolution apparatus 2 at the earlier sampling times. At the later sampling time points, the drug was released at a slightly faster rate in the proposed method as compared to the USP method. Furthermore, a more linear drug release and a higher total amount of drug release were achieved in the proposed method ( $95.8 \%$ of drug release by the proposed method as compared to $85.0 \%$ of drug release by the USP method). The proposed method allowed easy sampling and eliminated the tablet sticking to the agitating device (magnetic stirrer). The proposed test may show good in vivo in vitro correlation since an attempt is made to mimic the in vivo conditions. The results of in vitro drug dissolution were fitted to zero order model. The values of correlation coefficient were found to be 0.99 and 0.95 respectively with the proposed method and USP method. The calculated values of time for $50 \%$ drug release $\left(t_{50}\right)$ and $80 \%$ drug release $\left(t_{80}\right)$ were found to be 397 and 642 minutes respectively. Table II shows the comparison between the different dissolution methods $(11,12)$. Table III contrasts the features of the Rossett-Rice test and the proposed method. 
Moore and Flanner (13) proposed an equation for calculating similarity factor $\left(f_{2}\right)$. Value of $f_{2}$ between 50 and 100 ensures sameness or equivalence of the two dissolution profiles (14). The calculated value of $f_{2}$ was 57 , indicating similarity at $10 \%$ difference between USP method (reference) and proposed method (test). Shah et al. (15) reported that $f_{2}$ equal to 65 indicates similarity at $5 \%$ difference. Therefore, at $5 \%$ difference, the dissolution profiles cannot be considered as similar.

Two-tiered dissolution tests in simulated gastric fluid with or without pepsin may be adopted in the proposed method. Further studies may be carried out with a different rate of $\mathrm{HCl}$ addition (2-4 $\mathrm{ml} / \mathrm{min}$ ), with a different volume of $\mathrm{HCl}$ in the beaker (up to $100 \mathrm{ml}$ ) and with a different agitation rate.

\section{Conclusion}

In the present study, a novel in vitro dissolution test methodology is proposed wherein the gastric acid secretion rate, gastric volume and gastric emptying are mimicked. The proposed method showed dissimilar dissolution with respect to USP method 2 at $5 \%$ difference. The dosage form is surrounded by fresh dissolution medium as seen in a flow-through cell. Throughout the study, sticking of the tablet to the agitation device was not observed. Hence, minimum variation between and within batches may be expected. The test allowed easy sampling. The drug release in the proposed method followed zero-order kinetics. The proposed test may be adopted as a quality control test or for establishing in vitro in vivo correlation.

Academicians and researchers may adopt this method due to its simplicity. The proposed method can also be used for other drugs such as ciprofloxacin, cizapride, diltiazem, misoprostol, diazepam, L-Dopa, furosemide, captopril, metronidazole, and so on, which are potential candidates for a floating drug delivery system.

\section{Acknowledgement}

We are thankful to Intas Pharmaceuticals Ltd. and Torrent Pharmaceuticals Ltd. for providing carbamazepine and hydroxypropyl methylcellulose.

\section{References}

1. Streubel, A., Siepmann, J., Bodmeier, R., “Floating microparticles based on low density foam powder." Int. J. Pharm., 241, 279-292, 2002.

2. Moes, A. J., "Gastroretentive dosage forms.” Crit. Rev. Ther. Drug Carrier Syst. 10, 143-145, 1993.

3. Deshpande, A. A., Rhodes, C. T, Shah, N. H., Malick, A. W., "Controlled release drug delivery systems for prolonged gastric residence: an overview." Drug Dev. Ind. Pharm. 22, 531-539, 1996.
4. Rouge, N., Buri, P., Doelker, E., "Drug absorption sites in the gastrointestinal tract and dosage forms for site specific delivery." Int. J. Pharm. 136, 117-139, 1996.

5. Hwang, S. J., Park, H., Park, K., "Gastric retentive drug delivery systems." Crit. Rev. Ther. Drug Carrier Syst. 15, 243-284, 1998.

6. Singh, B. N., Kim, K. H., "Floating drug delivery systems: an approach to oral controlled drug delivery via gastric retention." J. Control. Release. 63, 235-259, 2000.

7. Desai, S., Bolton, S., "A floating controlled release drug delivery system. In vitro and in vivo evaluation." Pharm. Res. 10, 1321-1325, 1993.

8. Burns, S. J., Attwood, D., Barnwell, S. G., "Assessment of a dissolution vessel designed for use with floating and erodible dosage forms." Int. J. Pharm. 160, 213-218, 1998.

9. Durig, T., Fassihi, R., "Evaluation of floating and sticking extended release delivery systems: an unconventional dissolution test." J. Control. Release. 67, 37-44, 2000.

10. Splvey, R. J., and Goodhart, F. W., "In vitro acid reactivity of three commercial antacid tablets." Am. J. Hosp Pharm, 36(May), 660-663, 1979.

11. Rohrs, B. R., "Dissolution method development for poorly soluble compounds." Dissolution Technologies, 8 (3), 6-12, 2001.

12. Technical Brochure of Sotax, web site: www.Sotax.com.

13. Moore, J. W., and Flanner, H. H.," "Mathematical comparison of dissolution profile." P. T., 20 (6), 64-74, 1996.

14. US Food and Drug Administration, Rockville, MD USA (1997) Guidance for industry, Dissolution testing of immediate release solid oral dosage form.

15. Shah, V. P., Tsong, Y., Sathe, P., and Lin, J.,"In vitro dissolution profile comparison-statistics and analysis of the similarity factor $f_{2} . "$ Pharm. Res., 15(6), 889-896, 1998. 